\title{
Meta-analysis of progesterone supplementation during timed artificial insemination programs in dairy cows
}

\author{
R. S. Bisinotto, ${ }^{*}$ I. J. Lean, $†$ W. W. Thatcher, ${ }^{*}$ and J. E. P. Santos ${ }^{* 1}$ \\ *Department of Animal Sciences, D.H. Barron Reproductive and Perinatal Biology Research Program, University of Florida, Gainesville 32611 \\ †SBScibus, PO Box 660, Camden 2570, New South Wales, Australia
}

\section{ABSTRACT}

A systematic review of the literature was performed with the objective to evaluate the effects of progesterone supplementation using a single intravaginal insert during timed artificial insemination (AI) programs on fertility in lactating dairy cows. A total of 25 randomized controlled studies including 8,285 supplemented cows and 8,398 untreated controls were included in the meta-analysis. Information regarding the presence of corpus luteum (CL) at the initiation of the synchronization protocol was available for 6,883 supplemented cows and 6,879 untreated controls in 21 experiments. Studies were classified based on service number (first AI vs. resynchronized AI), use of presynchronization (yes vs. no), and insemination of cows in estrus during the synchronization protocol (inseminated in estrus and timed AI vs. timed AI only). Reproductive outcomes of interest were pregnancy per $\mathrm{AI}(\mathrm{P} / \mathrm{AI})$ measured on $\mathrm{d}$ 32 (27 to 42 ) and 60 (41 to 71) after AI, and pregnancy loss between d 32 and 60 of gestation. Random effects meta-analyses were conducted and treatment effect was summarized into a pooled risk ratio with the KnappHartung modification $\left(\mathrm{RR}_{\mathrm{K}+\mathrm{H}}\right)$. The effect of moderator variables was assessed using meta-regression analyses. Progesterone supplementation increased the risk of pregnancy on d $32\left[\mathrm{RR}_{\mathrm{K}+\mathrm{H}}=1.08 ; 95 \%\right.$ confidence interval $(\mathrm{CI})=1.02-1.14]$ and 60 after $\mathrm{AI}\left(\mathrm{RR}_{\mathrm{K}+\mathrm{H}}=\right.$ $1.10 ; 95 \% \mathrm{CI}=1.03-1.17)$. The benefit of progesterone supplementation was observed mainly in cows lacking a CL at the initiation of the timed AI program (d 60: $\left.\mathrm{RR}_{\mathrm{K}+\mathrm{H}}=1.18 ; 95 \% \mathrm{CI}=1.07-1.30\right)$ rather than those with CL (d 60: $\left.\mathrm{RR}_{\mathrm{K}+\mathrm{H}}=1.06 ; 95 \% \mathrm{CI}=0.99-1.12\right)$. Progesterone supplementation benefited P/AI in studies in which all cows were inseminated at timed AI (d 60: $\mathrm{RR}_{\mathrm{K}+\mathrm{H}}=1.20 ; 95 \% \mathrm{CI}=1.10-1.29$ ), but not in studies in which cows could be inseminated in estrus during the timed AI program $\left(\mathrm{d}\right.$ 60: $\mathrm{RR}_{\mathrm{K}+\mathrm{H}}=1.04$; $95 \%$ CI $=0.92-1.16)$. Progesterone supplementation

Received October 9, 2014.

Accepted December 11, 2014.

${ }^{1}$ Corresponding author: jepsantos@ufl.edu tended to reduce the risk of pregnancy loss $\left(\mathrm{RR}_{\mathrm{K}+\mathrm{H}}=\right.$ $0.84 ; 95 \% \mathrm{CI}=0.67-1.00)$. Service number and presynchronization did not influence the effect of progesterone supplementation on fertility. In summary, progesterone supplementation using a single intravaginal insert during the timed AI program increased P/AI mostly in cows without CL and reduced the risk of pregnancy loss in lactating dairy cows. Insemination of cows in estrus during the synchronization protocol eliminated the benefit of supplemental progesterone on P/AI.

Key words: controlled internal drug release (CIDR), corpus luteum, progesterone, reproduction

\section{INTRODUCTION}

Mounting evidence indicates that insufficient concentrations of progesterone during the development of the ovulatory follicle is a major impediment for fertility in high-producing dairy cows subjected to timed AI programs (Bisinotto et al., 2014; Wiltbank et al., 2014). Approximately $30 \%$ of the cows lack a corpus luteum (CL) at the initiation of the synchronization protocol (Fricke et al., 2003; Stevenson et al., 2008; Bisinotto et al., 2010a), which encompasses anovular and estrous cyclic cows. This cohort, when subjected to timed AI protocols, ovulates first-wave follicles that develop under low concentrations of progesterone and result in reduced pregnancy per AI (P/AI) compared with herdmates whose follicles grow during diestrus (Bisinotto et al., 2010a; Denicol et al., 2012).

Lactating dairy cows have lower concentrations of progesterone in plasma during diestrus compared with nonlactating heifers (Sartori et al., 2004) because of the extensive catabolism by the splanchnic tissues resulting from increased feed intake (Sangsritavong et al., 2002; Wiltbank et al., 2014). Reduced progesterone concentrations has been linked to increased growth rate of the ovulatory follicle (Cerri et al., 2011b), impaired embryo quality (Rivera et al., 2011), and reduced P/ AI in lactating cows (Fonseca et al., 1983; Meisterling and Dailey, 1987). The reduced concentrations of progesterone in lactating cows compared with dairy heifers has been suggested as one of the reasons for 
the reduced fertility with onset of lactation (Sartori et al., 2002, 2004). Lactating cows classified as having low progesterone concentrations in the week preceding spontaneous estrus had less $\mathrm{P} / \mathrm{AI}$ than herdmates with high concentrations of progesterone during the same period (Folman et al., 1973; Fonseca et al., 1983; Meisterling and Dailey, 1987). Finally, dairy cows selected for high fertility, based on estimated breeding values, had greater progesterone concentrations during diestrus compared with contemporaneous herdmates selected against fertility traits (Moore et al., 2014). Although in many of the aforementioned studies the experimental designs did not allow for the establishment of causality, these results point out that high concentration of progesterone during follicle development is important for fertility in dairy cows. However, supplementing progesterone using a single intravaginal insert has not enhanced fertility in a consistent manner (Rabiee et al., 2004). Improved P/AI has been reported in some (Stevenson et al., 2006; Bisinotto et al., 2010b; Colazo et al., 2013), but not all studies (Galvão et al., 2004; Lima et al., 2009; Bilby et al., 2013; Chebel et al., 2013). Identifying the sources of this heterogeneity is critical not only for understanding the mechanisms by which progesterone before AI affects fertility, but also for the development of supplementation strategies that improve reproductive performance and optimize the use of hormones in dairy cows.

A single intravaginal insert increases progesterone concentrations in plasma of lactating dairy cows by approximately $0.8 \mathrm{ng} / \mathrm{mL}$ (Cerri et al., 2009a; Lima et al., 2009), which is less than typically observed in cows in diestrus. In fact, a narrative review of the literature using studies only with high-producing dairy cows suggested that response to a progesterone insert during the timed AI protocol did not improve P/AI of anovular cows (Bisinotto and Santos, 2011), but did improve that of cows in diestrus. Those authors suggested that a single insert delivers sufficient progesterone to improve fertility in estrous cyclic cows by incrementing plasma concentrations during the development of the ovulatory follicle (Bisinotto and Santos, 2011), which has been observed by others (Bartolome et al., 2009; Bisinotto et al., 2010b).

Progesterone supplementation during timed AI protocols improves synchrony of ovulation by minimizing the risk of ovulation before the day of scheduled AI. Presynchronization protocols also improve synchrony of ovulation by increasing the proportion of cows in early diestrus when the timed AI protocol initiates (Moreira et al., 2001). Thus, it is possible that response to progesterone supplementation might be influenced by presynchronizing the estrous cycle before timed AI. Finally, the benefit of progesterone supplementation can be diminished by insemination of cows in estrus during the timed AI program. Five to $7 \%$ of the cows enrolled in timed AI programs are observed in estrus between the first $\mathrm{GnRH}$ and the $\mathrm{PGF}_{2 \alpha}$ injection (Chebel et al., 2013; Bisinotto et al., 2015). These cows that show early estrus are unlikely to become pregnant at timed AI. Progesterone supplementation prevents the occurrence of spontaneous estrus, thereby benefiting $\mathrm{P} / \mathrm{AI}$ when cows are inseminated at a fixed time (Stevenson et al., 2006). Conversely, delaying ovulation with supplemental progesterone prolongs the period of follicular dominance, which might reduce fertility in herds that inseminate cows in estrus during the timed AI program (Bleach et al., 2004; Cerri et al., 2009b).

Individual studies often encompass a limited number of herds with similar management practices. Therefore, this meta-analysis was designed to evaluate the effects of progesterone supplementation during the timed AI program across different managerial and physiological conditions. The main hypothesis of the present study was that supplementation with progesterone using a single intravaginal insert increases $\mathrm{P} / \mathrm{AI}$ and decreases pregnancy loss in lactating dairy cows. Moreover, it was anticipated that the benefits of supplemental progesterone would be observed mainly in cows with CL at the initiation of the timed AI program, those not subjected to presynchronization, and in studies in which detection of estrus was not performed.

\section{MATERIALS AND METHODS}

\section{Literature Search}

The literature search was conducted in PubMed (http://www.ncbi.nlm.nih.gov/pubmed), ScienceDirect (http://www.sciencedirect.com), and Google Scholar (http://scholar.google.com) using the keywords dairy cow and progesterone. A total of 1,539, 7,611, and 25,200 results were obtained in each engine, respectively. Additional studies were obtained directly from researchers in the field of reproductive biology. Results from the online search and personal communications were assessed individually for the initial screening to be considered for the meta-analysis.

\section{Inclusion and Exclusion Criteria}

We considered only randomized controlled studies using a single intravaginal insert during the timed AI program that measured pregnancy outcomes in lactating dairy cows. Hence, studies in which progesterone supplementation occurred before the initiation of the timed AI program as a presynchronization strategy or after insemination were not included. Studies were 
excluded from the data set if supplementation with progesterone was performed using multiple inserts (n $=2$ ), if the synchronization protocol was not the same for supplemented and nonsupplemented cows $(\mathrm{n}=1)$, and if only cows with ovarian cysts were used ( $\mathrm{n}=$ $3)$. Studies conducted with cohort of cows receiving or not receiving presynchronization, or cows subjected to resynchronization in different intervals after previous AI, were subdivided to reduce the heterogeneity within study and improve the estimation for effects of moderator variables. Based on these criteria, the meta-analysis included a total of 25 studies from 19 publications composed of 8,285 cows supplemented with progesterone and 8,398 untreated controls. Of the 25 studies used, 23 were conducted with high-producing cows under confinement in herds in the United States, Canada, and Turkey, and 2 were conducted with grazing cows in herds in Ireland and New Zealand.

\section{Data Extraction}

Data extraction was performed by a single investigator (R. S. Bisinotto) and validated by 2 coauthors (W. W. Thatcher and J. E. P. Santos). For each study, recorded information included authors, year of publication, service number, use of presynchronization, and insemination of cows in estrus during the timed AI program (Table 1). Service number was defined based on whether cows received the first AI postpartum or resynchronized AI. Presynchronization programs based on $\mathrm{GnRH}$ and $\mathrm{PGF}_{2 \alpha}$ or $\mathrm{PGF}_{2 \alpha}$ alone were grouped together and studies were classified as having presynchronized or nonpresynchronized timed AI. Studies were classified as those in which cows could only be inseminated on the day of timed AI or those in which cows were observed for signs of estrus during the synchronization protocol and had the chance to be inseminated before the scheduled timed AI.

Pregnancy status was evaluated twice after AI, except for 4 studies from 3 publications (El-Zarkouny et al., 2004; Melendez et al., 2006; Walsh et al., 2007). The ranges for the first and second pregnancy diagnoses were 27 to 42 and 41 to $71 \mathrm{~d}$ after AI, respectively. For simplicity, the time at which pregnancy was evaluated will be referred to as d 32 and 60 after AI throughout the manuscript. Reproductive outcomes were recorded separately for control and treated groups and included the number of cows diagnosed pregnant on d 32 and 60 after $\mathrm{AI}$, total number of cows subjected to $\mathrm{AI}$, and the number of cows that lost a pregnancy between $\mathrm{d} 32$ and 60 of gestation. Within study, P/AI was calculated as the number of cows diagnosed pregnant on $\mathrm{d} 32$ and 60 after AI divided by the total number of cows inseminated (Table 1). For studies in which a single pregnancy diagnosis was performed, the results observed on d 32 were repeated on $\mathrm{d} 60$. The aforementioned was performed to ensure that all studies were accounted for in the analyses of the effect progesterone supplementation on final $\mathrm{P} / \mathrm{AI}$, thereby minimizing potential publication bias on the final evaluation of pregnancy. Pregnancy loss was calculated as the number of cows diagnosed pregnant on d 32 that lost the pregnancy before d 60 divided by the number of cows diagnosed pregnant on d 32. As opposed to the analysis of P/AI, studies in which a single pregnancy diagnosis was performed were not included in the analysis of pregnancy loss.

Information regarding the presence or absence of CL at the initiation of the timed AI program was available for 6,883 cows supplemented with progesterone and 6,879 untreated controls in 21 studies from 17 publications of the original selected database (Table 2). Presence or absence of CL on the day of the first GnRH injection of the synchronization protocol was determined by examination of the ovaries using ultrasonography $(\mathrm{n}=8)$ or based on concentrations of progesterone in blood greater than $1.0 \mathrm{ng} / \mathrm{mL}(\mathrm{n}=13)$.

\section{Timed Al Protocols and Treatments}

Within study cows received the same timed AI program. Cows subjected to the 5-d Ovsynch protocol received an injection of $\mathrm{GnRH}$ on $\mathrm{d} 0$, followed by injections of $\mathrm{PGF}_{2 \alpha}$ on $\mathrm{d} 5$ and 6 , a second injection of $\mathrm{GnRH}$ on d 7.7, and timed AI on d 8 ( $\mathrm{n}=3$ studies). Cows subjected to the Ovsynch protocol received an injection of GnRH on d 0 followed by an injection of $\mathrm{PGF}_{2 \alpha}$ on $\mathrm{d}$ 7. The second GnRH injection and timed AI were performed, respectively, on d 9 and $9.3(\mathrm{n}=2$ studies), 9 and 10 ( $\mathrm{n}=2$ studies), 9.5 and $10.3(\mathrm{n}=1$ study), or 9.3 and 10 ( $\mathrm{n}=12$ studies). Cows subjected to the Cosynch protocol received an injection of GnRH on $\mathrm{d} 0$, followed by an injection of $\mathrm{PGF}_{2 \alpha}$ on $\mathrm{d} 7$, and a second injection of GnRH concurrently with timed AI on d 10 ( $\mathrm{n}=3$ studies). Cows subjected to the Heatsynch protocol received an injection of $\mathrm{GnRH}$ on $\mathrm{d}$ 0 , followed by an injection of $\mathrm{PGF}_{2 \alpha}$ on $\mathrm{d} 7$, an injection of estradiol cypionate on d 8, and timed AI on d 10 (n $=2$ studies).

Control cows received no additional treatment. Treated cows received a single controlled internal-drug release (Eazi-Breed CIDR Cattle Insert, Zoetis, Madison, NJ) containing 1.38 or $1.9 \mathrm{~g}$ of progesterone (n $=22$ studies) or a progesterone-releasing intravaginal device (PRID, Vétoquinol S.A., Lure, France) containing $1.55 \mathrm{~g}$ of progesterone ( $\mathrm{n}=3$ studies) on the day of the first GnRH injection. Inserts were removed concurrently with the injection of $\mathrm{PGF}_{2 \alpha}$ ( $\mathrm{n}=24$ studies) or 24 h later ( $\mathrm{n}=1$ study). 
Table 1. Classification of studies depending on moderator variables and effect of progesterone supplementation during the timed AI program on pregnancy per $\mathrm{AI}(\mathrm{P} / \mathrm{AI})$ and risk of pregnancy loss in lactating dairy cows

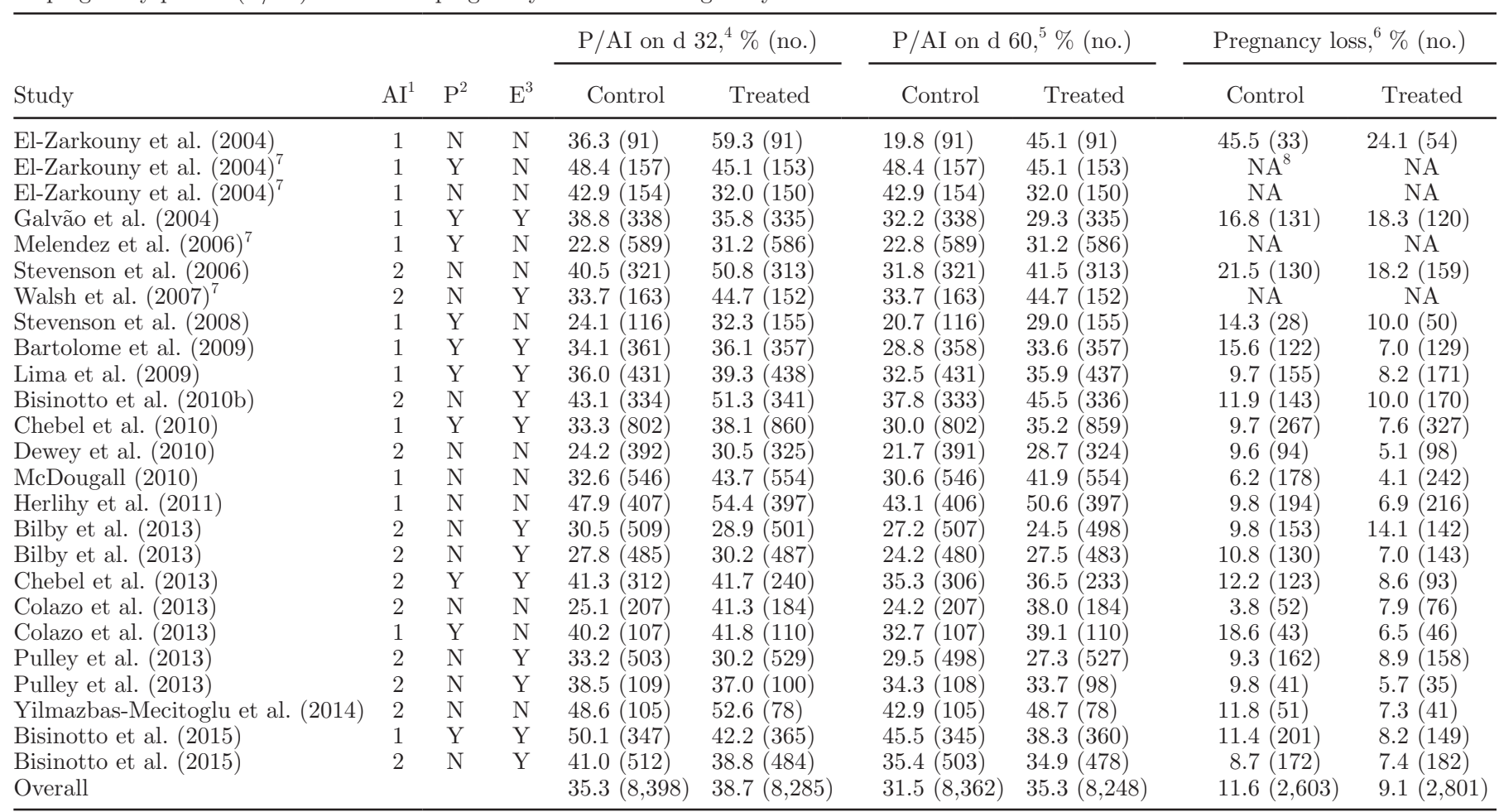

${ }^{1}$ Service number $(1=$ first AI postpartum vs. 2 = resynchronized AI).

${ }^{2}$ Use of presynchronization before the timed AI program ( $\mathrm{N}=$ no vs. $\mathrm{Y}=$ yes).

${ }^{3}$ Detection of estrus during the timed AI program ( $\mathrm{N}=$ no vs. $\mathrm{Y}=$ yes).

${ }^{4}$ Pregnancy per AI was calculated as the number of pregnant cows divided by the number of cows that received AI. Pregnancy per AI on d 32 was evaluated from 27 to $42 \mathrm{~d}$ after AI.

${ }^{5}$ Pregnancy per AI on d 60 was evaluated from 41 to 71 d after AI.

${ }^{6}$ Pregnancy loss was calculated as the number of cows that lost a pregnancy between d 32 and 60 after AI divided by the number of cows diagnosed pregnant on d 32 .

${ }^{7}$ Studies in which a single pregnancy diagnosis was performed and no pregnancy loss was available. The results of $\mathrm{P} / \mathrm{AI}$ were repeated on $\mathrm{d} 32$ and 60 for computation of effects of treatment on pregnancy.

${ }^{8} \mathrm{NA}=$ not available.

\section{Statistical Analyses}

The meta-analysis was conducted using Stata version 13.1 (StataCorp, College Station, TX). Random effects models were fitted to evaluate the effects of progesterone supplementation during the timed AI program on $\mathrm{P} / \mathrm{AI}$ and pregnancy loss in lactating dairy cows. The overall effect size was summarized into a pooled risk ratio adjusted using the Knapp-Hartung modification $\left(\mathbf{R R}_{\mathrm{K}+\mathbf{H}}\right)$ with a $95 \%$ CI as described elsewhere (DerSimonian and Laird, 1986; Knapp and Hartung, 2003; Rabiee and Lean, 2013). Control cows were the reference for comparison in all analyses. Unadjusted P/AI and pregnancy loss calculated from the raw data were presented to illustrate the absolute difference among treatments. The risk ratio depicted by individual studies as well as the overall $\mathrm{RR}_{\mathrm{K}+\mathrm{H}}$ were presented using forest plots.
Heterogeneity was assessed using a $\chi^{2}$ test with the null hypothesis that the effect size did not differ among studies and $P \leq 0.10$ was considered indicative of heterogeneity (Egger and Smith, 2001). The proportion of total variation accounted for by heterogeneity, rather than sampling error $\left(\boldsymbol{I}^{2}\right)$, was calculated as described previously (Higgins et al., 2003). Possible sources of heterogeneity were explored using a meta-regression approach (Knapp and Hartung, 2003). Separate models were built to evaluate the effects of service number, use of presynchronization, and insemination of cows in estrus during the timed AI program on the effects of progesterone supplementation. The effect of each moderator variable was expressed as the difference in risk ratio $\left(\mathbf{R D}_{\mathbf{K}+\mathbf{H}}\right)$ from the reference group followed by its $95 \%$ CI. For each meta-regression analysis, the reference group included the studies in which cows 
Table 2. Effect of progesterone supplementation during the timed AI program on pregnancy per AI (P/AI) and pregnancy loss in lactating dairy cows depending on the presence of corpora lutea (CL) at the initiation of the synchronization protocol

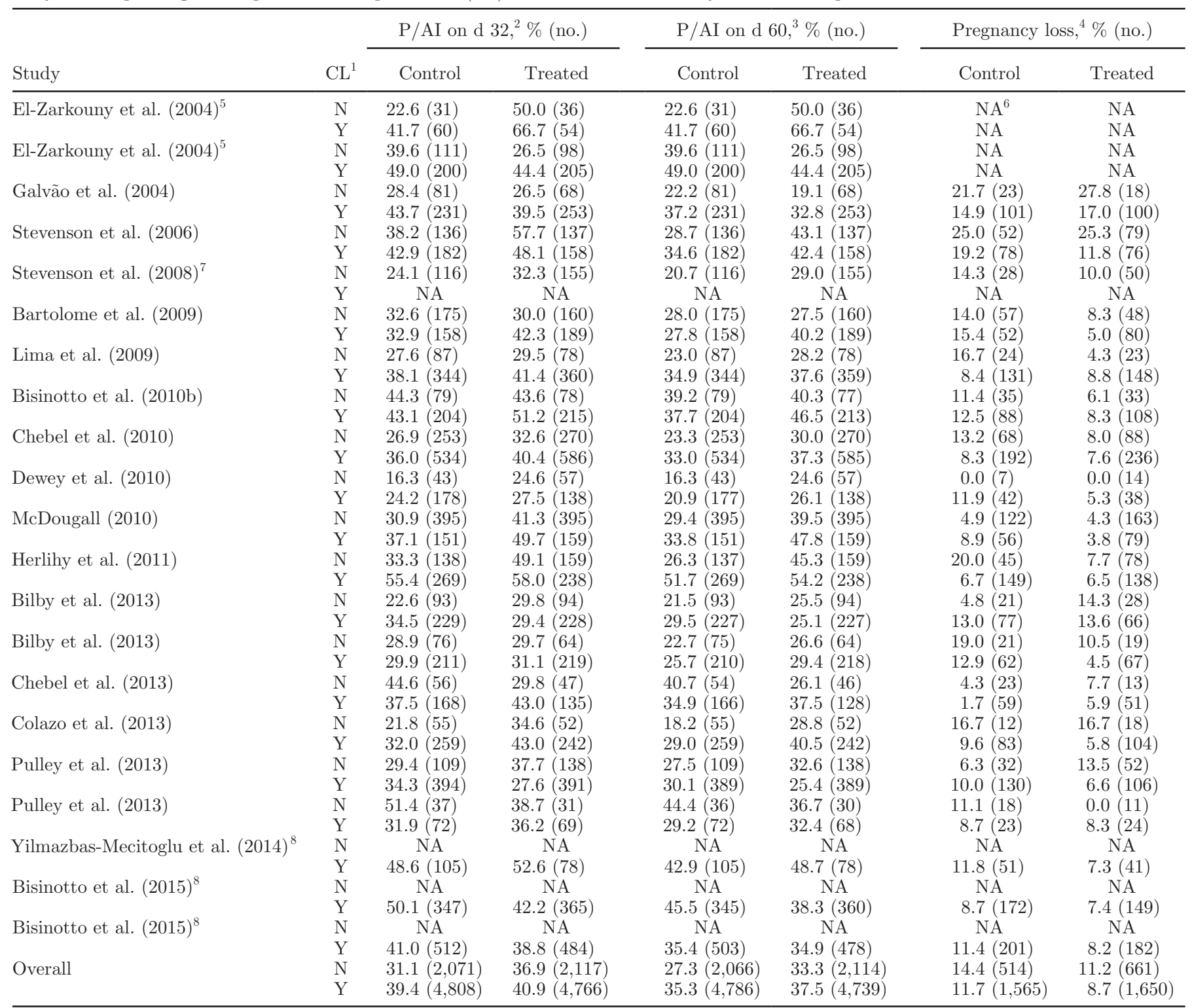

${ }^{1}$ The presence of CL at the initiation of the timed AI program was determined by examination of the ovaries using ultrasonography or based on concentrations of progesterone in blood greater than $1.0 \mathrm{ng} / \mathrm{mL}(\mathrm{N}=$ no CL present vs. $\mathrm{Y}=\mathrm{CL}$ present).

${ }^{2}$ Pregnancy per AI was calculated as the number of pregnant cows divided by the number of cows that received AI. Pregnancy per AI on d 32 was evaluated from 27 to $42 \mathrm{~d}$ after AI.

${ }^{3}$ Pregnancy per AI on d 60 was evaluated from 41 to $71 \mathrm{~d}$ after AI.

${ }^{4}$ Pregnancy loss was calculated as the number of cows that lost a pregnancy between d 32 and 60 after AI divided by the number of cows diagnosed pregnant on d 32 .

${ }^{5}$ Studies in which a single pregnancy diagnosis was performed and no pregnancy loss was available. The results of P/AI were repeated on d 32 and 60 for computation of effects of treatment on pregnancy.

${ }^{6} \mathrm{NA}=$ not available.

${ }^{7}$ Only cows without CL were enrolled in the study.

${ }^{8}$ Only cows with CL were enrolled in the study.

were subjected to first AI, those with cows not presynchronized, and those with no detection of estrus. The proportion of between-study variance explained by each moderator variable was expressed using an adjusted $R^{2}$.
Separate analyses were conducted to evaluate the effects of progesterone supplementation on $\mathrm{P} / \mathrm{AI}$ and pregnancy loss depending on the presence of CL at the initiation of the timed AI program. Studies were 
partitioned into cows with and without CL, and each subdivision was considered an individual experiment. Meta-analyses were performed for P/AI $(\mathrm{n}=38)$ and pregnancy loss $(\mathrm{n}=33)$. Meta-regression analyses were used to assess the effects of service number, presynchronization, detection of estrus during the timed AI program, and CL status. Subgroup analyses were performed on cows with and without CL at the initiation of the timed AI program and the risk ratio for the effect of progesterone supplementation was summarized into a pooled risk ratio $\left(\mathbf{R R}_{\mathbf{D}+\mathbf{L}}\right)$ and its $95 \%$ CI (DerSimonian and Laird, 1986). Monte Carlo permutation tests were conducted to evaluate the joint effect of detection of estrus and CL status on P/AI. A total of 5,000 permutations were used and $P$-values were adjusted for multiplicity.

Visual evaluation of contour-enhanced funnel plots was performed to assess potential publication bias (Lean et al., 2009). For all analyses, differences with $P$ $\leq 0.05$ were considered significant and those with 0.05 $<P \leq 0.10$ were considered tendencies.

\section{RESULTS}

\section{Overall Effect of Progesterone Supplementation on P/AI}

The incorporation of a single intravaginal insert containing progesterone to the timed AI program increased $(P<0.01)$ the risk of pregnancy in lactating dairy cows on $\mathrm{d} 32\left(\mathrm{RR}_{\mathrm{K}+\mathrm{H}}=1.08 ; 95 \% \mathrm{CI}=1.02-1.14\right)$ and 60 after $\mathrm{AI}\left(\mathrm{RR}_{\mathrm{K}+\mathrm{H}}=1.10 ; 95 \% \mathrm{CI}=1.03-1.17\right.$; Figure 1). Risk ratios indicating numerically greater $\mathrm{P} /$ $\mathrm{AI}$ in cows supplemented with progesterone compared with untreated controls were observed in 17 of the 25 studies. Based on the raw data, the increments in $\mathrm{P} /$ AI between control and supplemented cows were of 3.4 percentage units on d 32 (35.3 vs. $38.7 \%)$ and 3.8 percentage units on d 60 after AI (31.5 vs. $35.3 \%$ ). Although the proportion of between-study variation accounted for by heterogeneity was small, 20.6 to $27.2 \%$, the $\chi^{2}$ test indicated that sources of heterogeneity were associated $(P=0.10)$ with the variability of the effect size among studies. Meta-regression analyses showed that inseminating cows in estrus during the synchronization protocol reduced $(P=0.01)$ the benefit of progesterone supplementation by 87.5 and $84.2 \%$ on d 32 and 60 after AI, respectively (Table 3). In fact, progesterone supplementation benefited $(P<0.001) \mathrm{P} /$ $\mathrm{AI}$ in studies in which all cows were inseminated at fixed time $\left(\mathrm{d} 60: \mathrm{RR}_{\mathrm{K}+\mathrm{H}}=1.20 ; 95 \% \mathrm{CI}=1.10-1.29\right.$; 12 studies with 6,288 cows $)$, but not $(P=0.52)$ in studies in which cows could be inseminated in estrus during the timed AI program $\left(\mathrm{d} 60: \mathrm{RR}_{\mathrm{K}+\mathrm{H}}=1.04 ; 95 \% \mathrm{CI}=\right.$
0.92-1.16; 13 studies with 10,395 cows). The reduced benefit of progesterone when detection of estrus was implemented was caused by an increased number of studies showing a negative effect of exogenous progesterone on $\mathrm{P} / \mathrm{AI}$ and also by reduced increases in the risk of pregnancy among the studies that observed a positive effect of progesterone supplementation during timed AI protocols (Figure 2). In contrast, the effect of progesterone supplementation was not altered by service number or the use of presynchronization. Based on the visual evaluation of the funnel plots, all studies with a treatment effect $(P<0.10)$ showed a benefit from supplementation with progesterone (Figure 3A). This pattern was caused mainly by a shift of all studies toward a positive treatment effect rather than an asymmetry on effect size estimates, thereby providing no evidence of publication bias.

\section{Effects of Progesterone Supplementation on P/AI Depending on the Presence of $C L$}

Supplementation with progesterone increased $(P<$ $0.01)$ the risk of pregnancy on $\mathrm{d} 32\left(\mathrm{RR}_{\mathrm{K}+\mathrm{H}}=1.07 ; 95 \%\right.$ $\mathrm{CI}=1.02-1.12)$ and 60 after $\mathrm{AI}\left(\mathrm{RR}_{\mathrm{K}+\mathrm{H}}=1.10 ; 95 \%\right.$ $\mathrm{CI}=1.04-1.15)$ in the subset of cows with information regarding the presence of CL. Contrary to the initial hypothesis, progesterone supplementation improved $\mathrm{P} /$ AI mostly in cows lacking a CL at the initiation of the timed AI protocol (Figure 4). Among the cows without $\mathrm{CL}$, progesterone supplementation increased $(P<0.01)$ $\mathrm{P} / \mathrm{AI}$ on $\mathrm{d} 32\left(\mathrm{RR}_{\mathrm{D}+\mathrm{L}}=1.14 ; 95 \% \mathrm{CI}=1.04-1.25\right)$ and 60 after $\mathrm{AI}\left(\mathrm{RR}_{\mathrm{D}+\mathrm{L}}=1.16 ; 95 \% \mathrm{CI}=1.06-1.29\right)$ compared with untreated controls. Supplementing progesterone did not affect $(P=0.28) \mathrm{P} / \mathrm{AI}$ on $\mathrm{d} 32$ after insemination in cows with $\mathrm{CL}$ at the initiation of the timed AI program $\left(\mathrm{RR}_{\mathrm{D}+\mathrm{L}}=1.03 ; 95 \% \mathrm{CI}=\right.$ $0.97-1.08)$; however, treatment tended $(P=0.09)$ to increase $\mathrm{P} / \mathrm{AI}$ on $\mathrm{d} 60$ after insemination compared with nonsupplemented control cows $\left(\mathrm{RR}_{\mathrm{K}+\mathrm{H}}=1.05 ; 95 \% \mathrm{CI}\right.$ $=0.99-1.11$.

Insemination of cows in estrus during the synchronization protocol reduced $(P \leq 0.05)$ the benefit of progesterone supplementation independently of the presence of CL at the initiation of the timed AI program (Table 4). Progesterone improved P/AI by $25 \%$ (RR $=1.25)$ on $\mathrm{d} 60$ after insemination, and detection of estrus reduced this benefit $\left(\mathrm{RD}_{\mathrm{K}+\mathrm{H}}=-0.14\right)$, resulting in a nonsignificant increase in $\mathrm{P} / \mathrm{AI}$ in supplemented cows $(\mathrm{RR}=1.11)$. Interestingly, the joint evaluation of CL status and detection of estrus explained all the heterogeneity associated with the effect of progesterone supplementation on $\mathrm{P} / \mathrm{AI}\left(I^{2}=0.0 \%\right)$. The benefit of progesterone supplementation in cows with CL information was not affected by service number and use of 


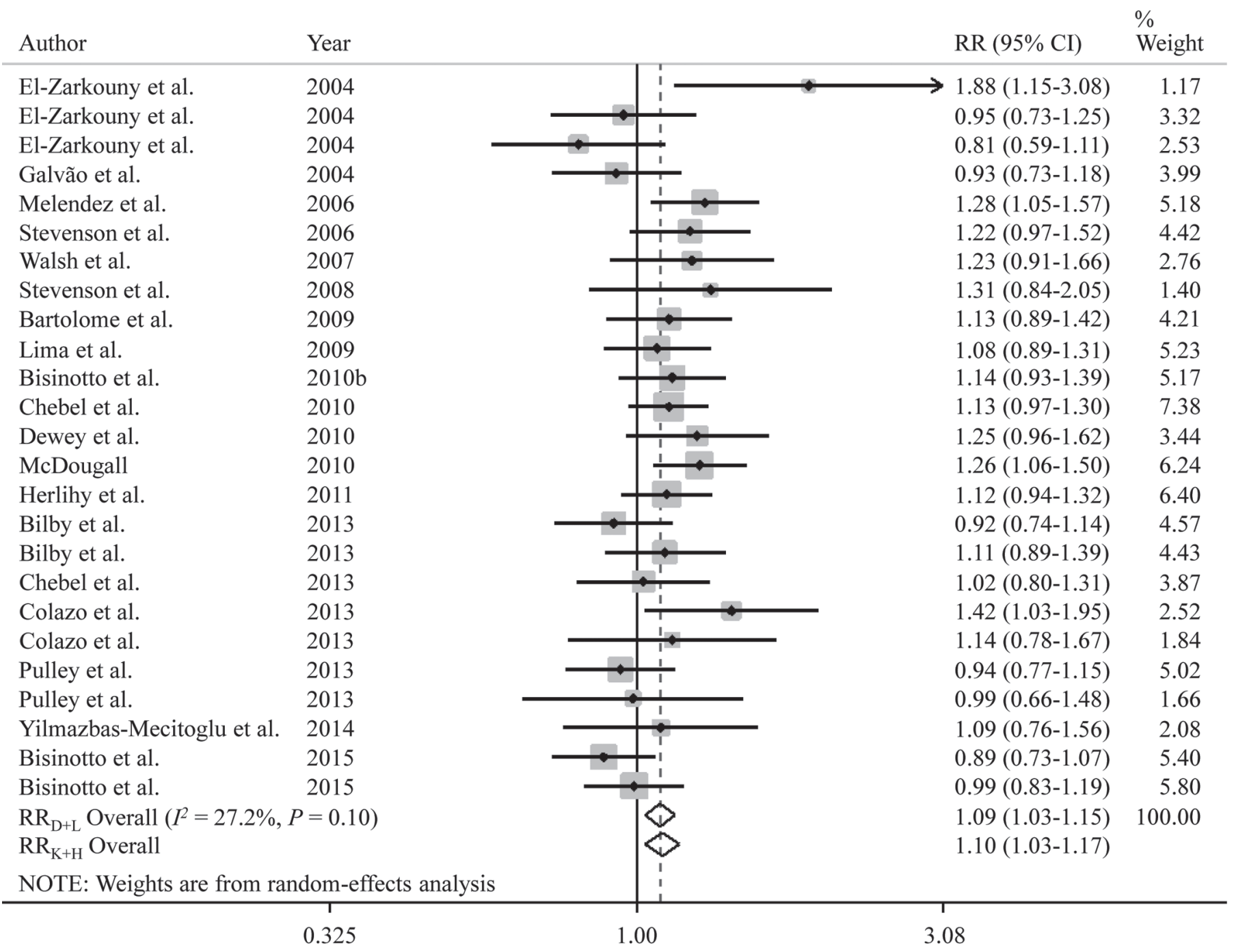

Figure 1. Effect of progesterone supplementation during the timed AI program on the risk of pregnancy on d 60 after AI. The weight (gray square), effect size (solid diamond), and the $95 \%$ CI (whiskers) were depicted for each study. The overall effect size was summarized into a pooled risk ratio $\left(\mathrm{RR}_{\mathrm{D}+\mathrm{L}}\right.$; dashed line) and the final treatment effect is presented with the Knapp-Hartung modification $\left(\mathrm{RR}_{\mathrm{K}+\mathrm{H}}\right)$. Control cows were the reference for comparison. The width of the open diamond indicates $\mathrm{RR}_{\mathrm{D}+\mathrm{L}}$ and $\mathrm{RR}_{\mathrm{K}+\mathrm{H}} 95 \%$ CI. $I^{2}=$ proportion of total variation of effect size estimates that is due to heterogeneity.

presynchronization. The funnel plots indicate a small asymmetry for small studies, suggesting limited evidence of publication bias (Figure 3B).

\section{Effects of Progesterone Supplementation on Pregnancy Loss}

Progesterone supplementation during the timed AI program tended to reduce $(P=0.09)$ the risk of pregnancy loss between d 32 and 60 of gestation (Figure 5), which corresponded to 2.5 percentage units based on the raw data, from 11.6 to $9.1 \%$ (Table 1 ). Risk ratios smaller than 1 were observed in 18 of the 21 studies included in the meta-analysis. No evidence of hetero- geneity was observed among studies. Accordingly, the benefit of progesterone supplementation in reducing pregnancy loss was not affected by service number, use of presynchronization, or detection of estrus throughout the timed AI program (Table 3). The reduced risk of pregnancy loss in response to progesterone supplementation was not affected $(P=0.75)$ by the presence of CL at the initiation of the synchronization protocol $\left(\mathrm{RD}_{\mathrm{K}+\mathrm{H}}=-0.06 ; 95 \% \mathrm{CI}=-0.46-0.33\right)$, and similar trends were observed in cows with and without a CL (Figure 6). The funnel plot for the analysis of pregnancy loss in all cows depicted an asymmetry because the majority of studies with a limited number of pregnant cows observed smaller risk of pregnancy loss in 
Table 3. Effect of moderator variables on the benefit of supplementing progesterone to lactating dairy cows during the timed AI program using a single intravaginal insert

\begin{tabular}{|c|c|c|c|c|c|c|}
\hline Moderator & \multicolumn{2}{|c|}{ Reference $^{1}$} & $\mathrm{RD}_{\mathrm{K}+\mathrm{H}^{3}}^{3}$ & $95 \%$ CI & Adjusted $\mathrm{R}^{2}$ & $P$-value \\
\hline $\mathrm{P} / \mathrm{AI} \mathrm{d} 60$ & 1.19 & (1.10 to 1.29$)$ & -0.16 & $(-0.28$ to -0.04$)$ & 0.80 & 0.01 \\
\hline Pregnancy loss & 0.76 & ( 0.47 to 1.05$)$ & 0.12 & $(-0.24$ to 0.48$)$ & $\mathrm{NE}$ & 0.49 \\
\hline \multicolumn{7}{|c|}{ Presynchronization } \\
\hline Pregnancy loss & 0.85 & (0.63 to 1.07$)$ & -0.04 & $(-0.39$ to 0.31$)$ & $\mathrm{NE}$ & 0.83 \\
\hline \multicolumn{7}{|l|}{ Service number } \\
\hline P/AI d 32 & 1.08 & (1.00 to 1.16$)$ & -0.01 & ( -0.12 to 0.11$)$ & -0.16 & 0.94 \\
\hline $\mathrm{P} / \mathrm{AI} \mathrm{d} 60$ & 1.11 & (1.01 to 1.21$)$ & -0.01 & $(-0.16$ to 0.13$)$ & -0.14 & 0.85 \\
\hline Pregnancy loss & 0.78 & (0.54 to 1.02$)$ & 0.12 & $(-0.22$ to 0.46$)$ & $\mathrm{NE}$ & 0.47 \\
\hline
\end{tabular}

${ }^{1}$ Reference groups were studies in which estrus was not detected during the timed AI program, no presynchronization was used, and cows received the first AI postpartum, respectively.

${ }^{2} \mathrm{RR}=$ risk ratio associated with progesterone supplementation in the reference group for each analysis (no detection of estrus, no presynchronization, first AI postpartum, respectively).

${ }^{3}$ Difference in the RR associated with the moderator variable calculated using the Knapp-Hartung modification. The adjusted $\mathrm{R}^{2}$ indicates the proportion of between-study variance explained by the moderator variable (NE = nonestimable). Negative values indicate that the moderator variable explain less of the heterogeneity than it would be expected by chance.

${ }^{4} \mathrm{P} / \mathrm{AI}=$ pregnancy per $\mathrm{AI}$.

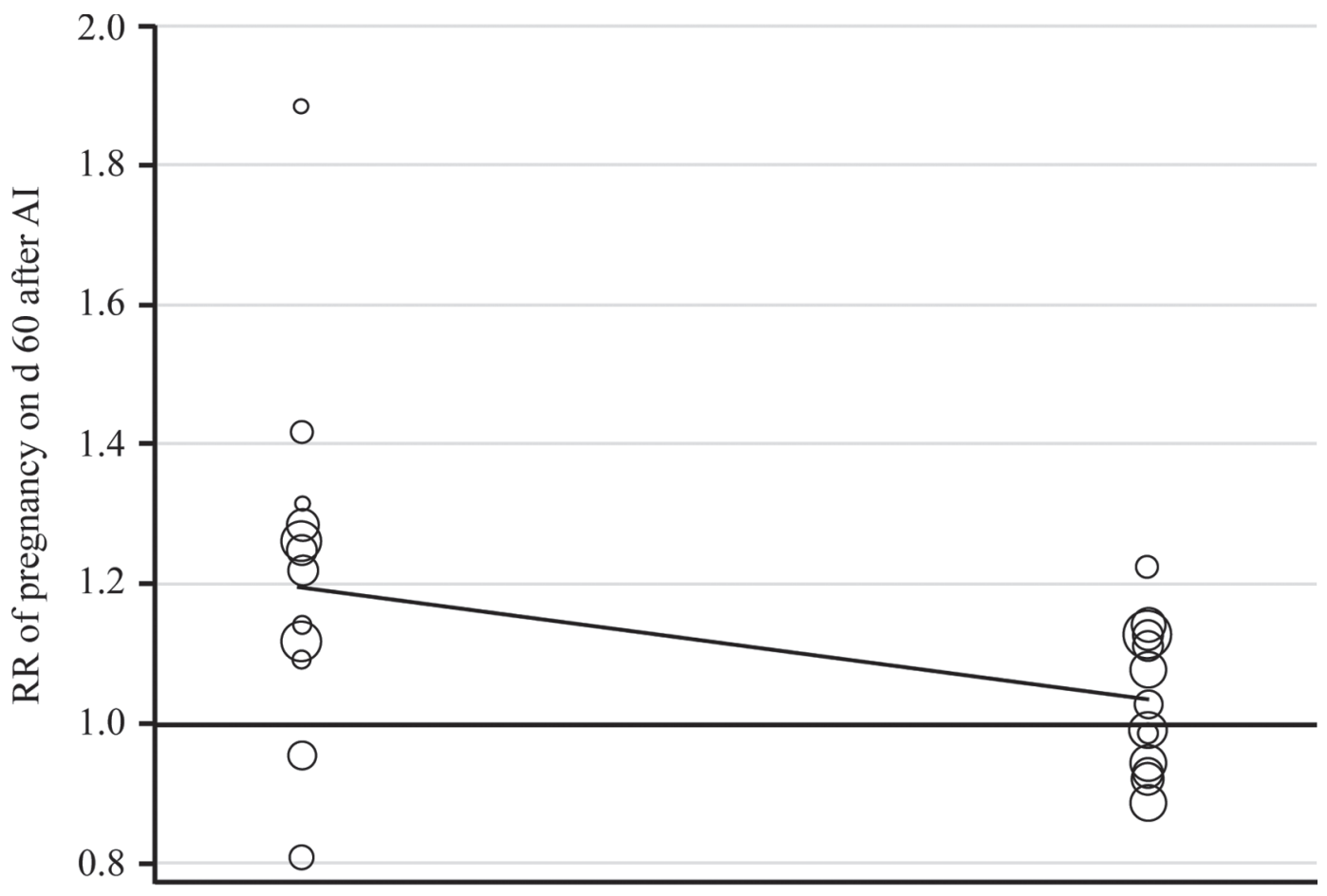

\section{No detection of estrus}

\section{Detection of estrus}

Figure 2. Effect of progesterone supplementation during the timed AI program on the risk of pregnancy on d 60 after AI depending on detection of estrus. Untreated controls were the reference [risk ratio $(\mathrm{RR})=1.0$ ]. No detection of estrus $=$ studies in which no estrous detection was performed during the synchronization protocol and all cows received timed AI (12 studies with 6,288 cows). Detection of estrus $=$ studies in which cows in estrus during the synchronization protocol were inseminated before the scheduled timed AI (13 studies with 10,395 cows). The size of each circle is proportional to the weight of the study in the meta-analysis. 
supplemented cows (Figure 7A). A similar asymmetry was not observed in the subset of cows with information about the presence of CL at the initiation of the timed AI program (Figure 7B).

\section{DISCUSSION}

The results from the present study indicate that incorporating a single intravaginal insert containing progesterone to a timed AI program improved $\mathrm{P} / \mathrm{AI}$ and tended to reduce pregnancy loss in lactating dairy cows. The risk of pregnancy evaluated on d 60 after AI was $10 \%$ greater in supplemented cows compared with untreated controls, which represented an overall increase of 3.8 percentage units of pregnancy, from 31.5 to $35.3 \%$. Nevertheless, $84.2 \%$ of this benefit was observed in studies wherein cows were not observed and inseminated in estrus during the synchronization protocol. The risk of pregnancy on d 60 after AI was $19 \%$ greater in cows supplemented with progesterone compared with controls if no detection of estrus and AI were performed during the synchronization protocol. Conversely, progesterone supplementation increased the risk of pregnancy only by $3 \%$ if cows in estrus had the opportunity to be inseminated before the scheduled day of timed AI. This interaction between detected estrus and progesterone supplementation is critical for the management of reproduction in dairy herds, as insemination of cows in estrus explained approximately $80 \%$ of the variation in $\mathrm{P} / \mathrm{AI}$ among studies. Furthermore, these results suggest that one of the major reasons for the benefit of progesterone supplementation during timed AI programs is an improved synchrony of the estrous cycle that allows for increased P/AI when cows are inseminated at fixed time.

Cows that fail to ovulate at the initiation of the synchronization protocol are more likely to undergo spontaneous luteolysis and fail to have a synchronized ovulation following the final GnRH injection (Vasconcelos et al., 1999). The introduction of a single intravaginal insert concurrently with the first injection of $\mathrm{GnRH}$ has not reduced the proportion of cows that ovulate at the beginning of the synchronization protocol (Bisinotto et al., 2010b; Dewey et al., 2010; Colazo et al., 2013). Although a decrease in ovulation to the first $\mathrm{GnRH}$ was observed in anovular cows treated with progesterone (Stevenson et al., 2008), other studies did not detect a detrimental effect of progesterone supplementation in cows without CL even with the use of 2 intravaginal inserts (Denicol et al., 2012; Bisinotto et al., 2013). Conversely, supplementation with progesterone reduced the occurrence of premature ovulation before timed AI (Bisinotto et al., 2010b; Colazo et al., 2013) and increased the proportion of cows with a functional
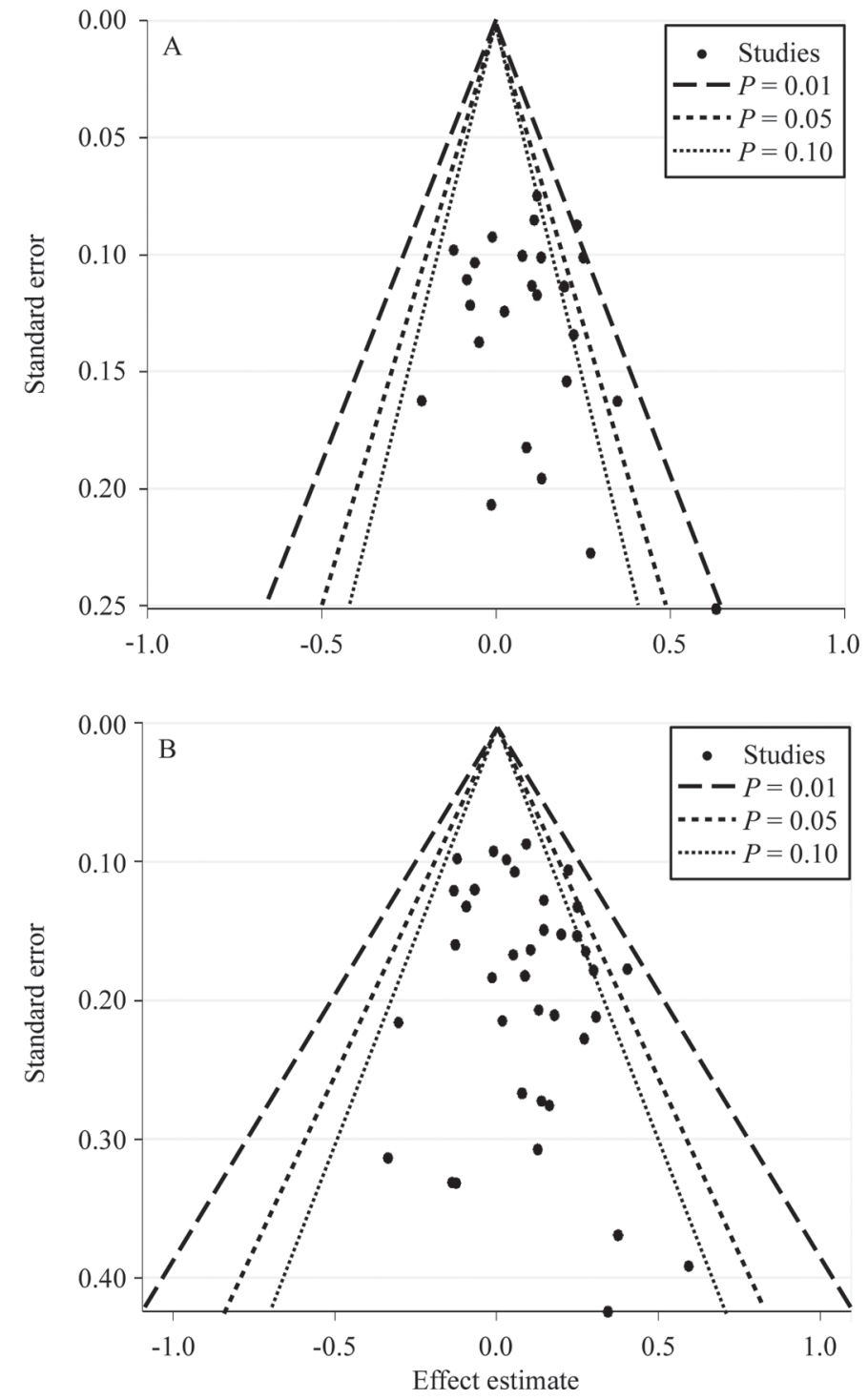

Figure 3. Contour-enhanced funnel plots for the risk of pregnancy on d 60 after $\mathrm{AI}$ in response to progesterone supplementation in all studies (A) or in studies with information on the presence of corpus luteum at the initiation of the timed AI program (B). Studies contained within the triangles have a significance value for the effect of progesterone supplementation greater than represented by the respective line (e.g., studies within the triangle contoured by the dotted lines have an effect of progesterone supplementation at $P>0.10)$. Standard errors are inversely proportional to the number of cows in the study (smaller standard errors represent larger studies). Effect estimates represent the increase in pregnancy per AI associated with progesterone supplementation (values greater than 0 indicate greater pregnancy per AI in cows supplemented with progesterone compared with controls).

CL 11 to $14 \mathrm{~d}$ after timed AI (Chebel et al., 2010); all of this indicates an improved synchrony of ovulation in response to the timed AI protocol when progesterone is supplemented. Stevenson et al. (2006) observed that use of a CIDR insert benefited fertility in cows lacking a CL at the injection of $\mathrm{PGF}_{2 \alpha}$, a cohort that included 


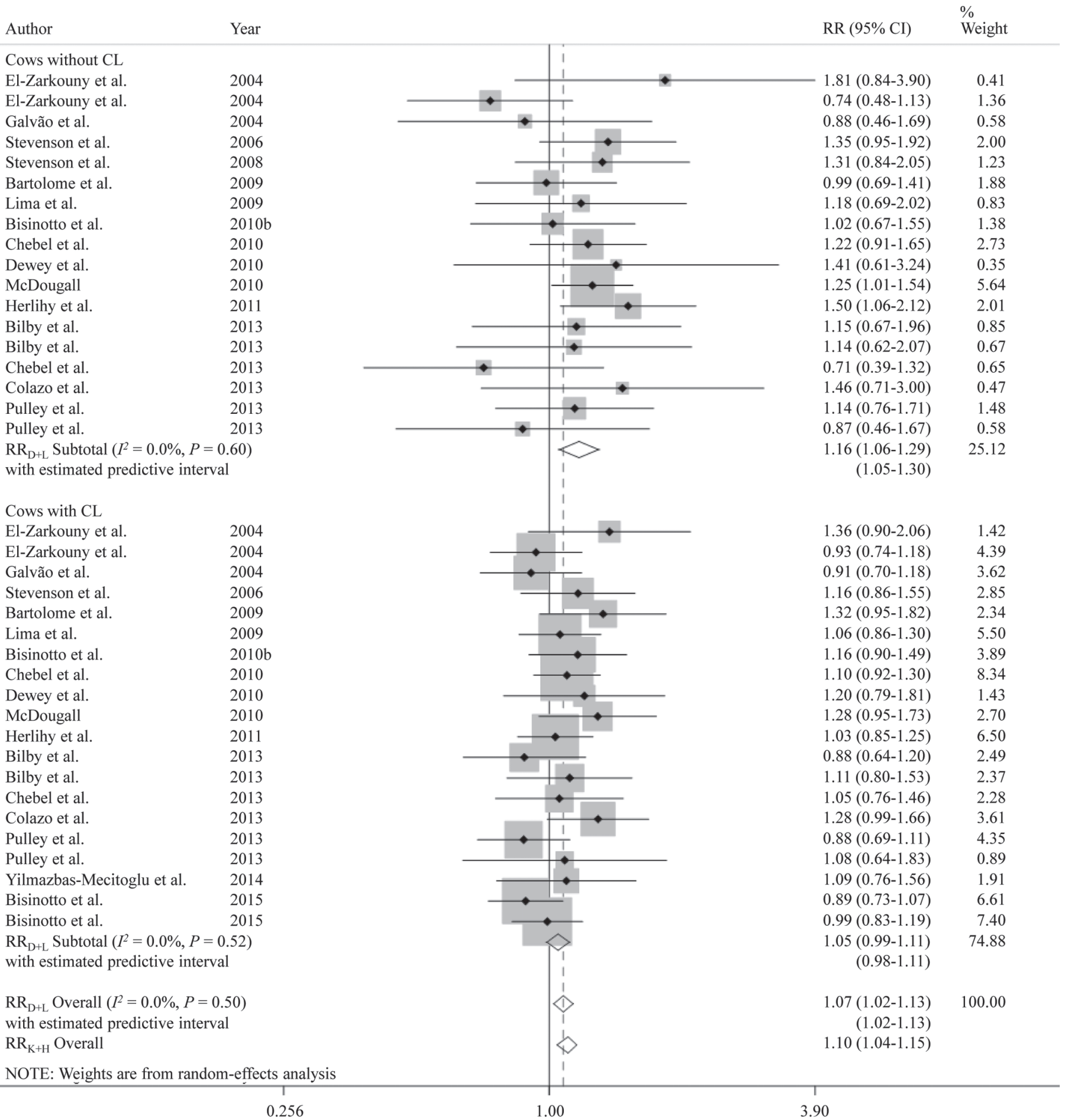

Figure 4. Effect of progesterone supplementation on the risk of pregnancy on d 60 after AI depending on the presence of corpus luteum (CL) at the initiation of the timed AI program. The weight (gray square), effect size (solid diamond), and the 95\% CI (whiskers) were depicted for each study. The overall effect size was summarized into a pooled risk ratio $\left(\mathrm{RR}_{\mathrm{D}+\mathrm{L}}\right.$; dashed line) and the final treatment effect is presented with the Knapp-Hartung modification $\left(\mathrm{RR}_{\mathrm{K}+\mathrm{H}}\right)$. Control cows were the reference for comparison. The width of the open diamond indicates $\mathrm{RR} \mathrm{D}_{\mathrm{L}}$ and $\mathrm{RR}_{\mathrm{K}+\mathrm{H}} 95 \%$ CI. $I^{2}=$ proportion of total variation of effect size estimates that is due to heterogeneity.

anovular cows that did not respond to the initial GnRH injection, and estrous cyclic cows that underwent spontaneous luteolysis. Bilby et al. (2013) assessed the ef- fect of progesterone supplementation in nonpregnant cows resynchronized on d 32 or 39 after a previous insemination. The proportions of cows that underwent 
Table 4. Evaluation of the effect of detection of estrus during the synchronization protocol on the response to progesterone supplementation depending on the presence of corpus luteum (CL) at the initiation of the timed AI program

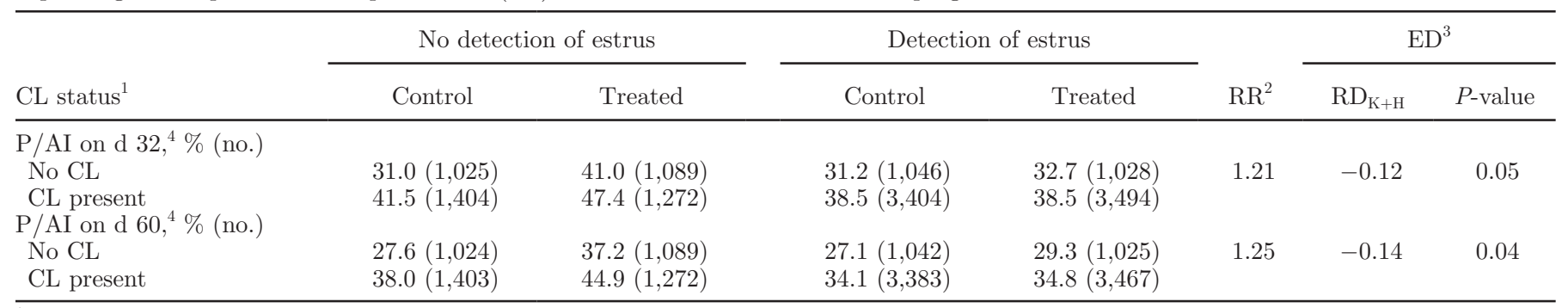

${ }^{1}$ Presence of CL at the initiation of the timed AI program determined by examination of the ovaries using ultrasonography or concentrations of progesterone in blood greater than $1.0 \mathrm{ng} / \mathrm{mL}$.

${ }^{2} \mathrm{RR}=$ risk ratio of the effect of progesterone supplementation conditional on the absence of CL and no detection of estrus.

${ }^{3} \mathrm{ED}=$ effect of detection of estrus on the response to progesterone supplementation during the timed AI protocol. $\mathrm{RD} \mathrm{K}_{\mathrm{H}}$ is the effect of imposing detection of estrus on the benefit of progesterone supplementation on P/AI (i.e., reduction in RR) obtained from the Monte Carlo permutation test. $P$-value adjusted for multiplicity.

${ }^{4}$ Pregnancy per AI from raw data.

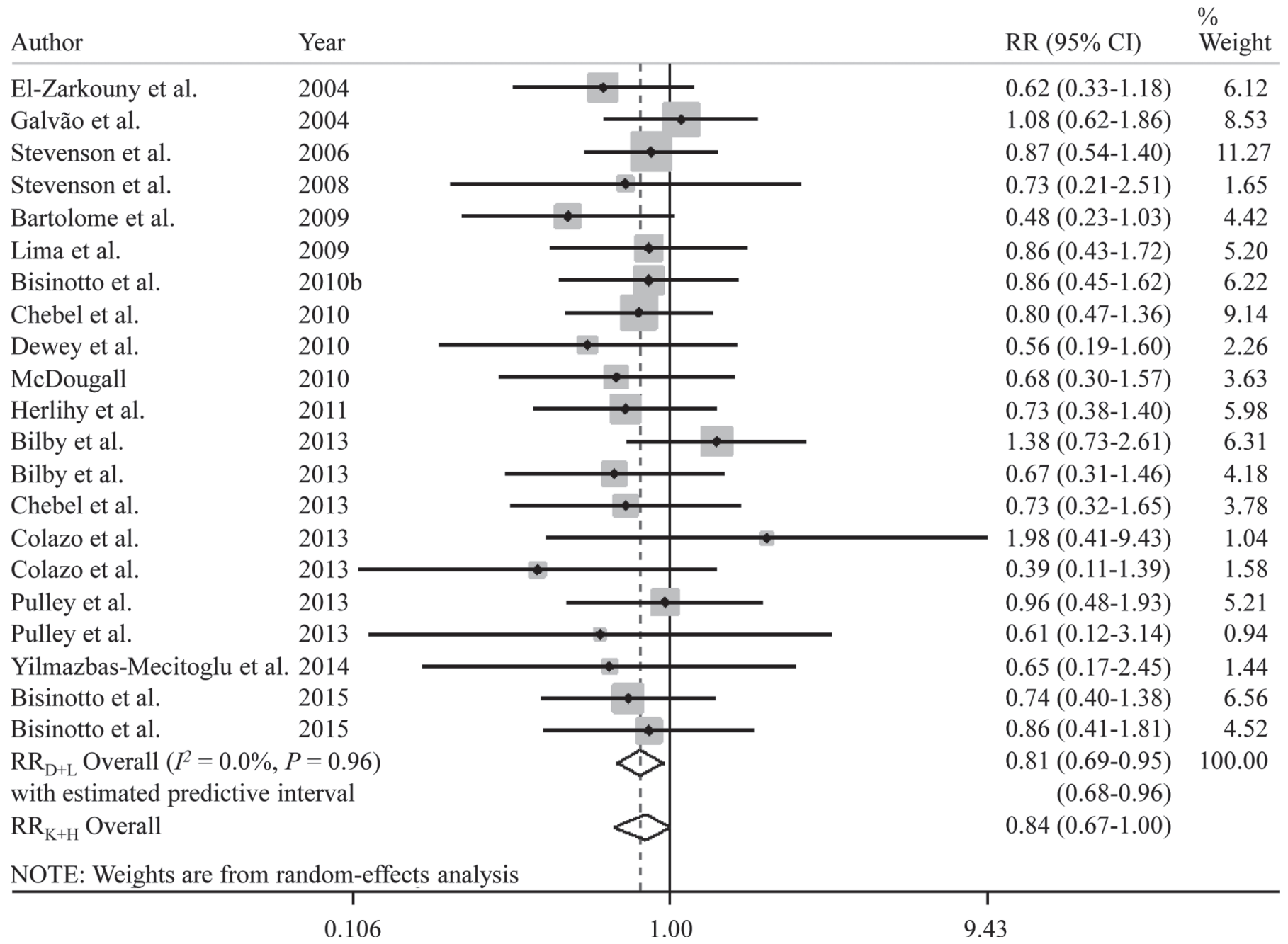

Figure 5. Effect of progesterone supplementation using a single intravaginal insert during the timed AI program on the risk of pregnancy loss between d 32 and 60 of gestation. The weight (gray square), effect size (solid diamond), and its 95\% CI (whiskers) were depicted for each study. The overall effect size was summarized into a pooled risk ratio $\left(\mathrm{RR}_{\mathrm{D}+\mathrm{L}}\right.$; dashed line) and the final treatment effect is presented with the Knapp-Hartung modification $\left(\mathrm{RR}_{\mathrm{K}+\mathrm{H}}\right)$. Control cows were the reference for comparison. The width of the open diamond indicates $\mathrm{RR}_{\mathrm{D}+\mathrm{L}}$ and $\mathrm{RR}_{\mathrm{K}+\mathrm{H}} 95 \%$ CI. $I^{2}=$ proportion of total variation of effect size estimates that is due to heterogeneity. 


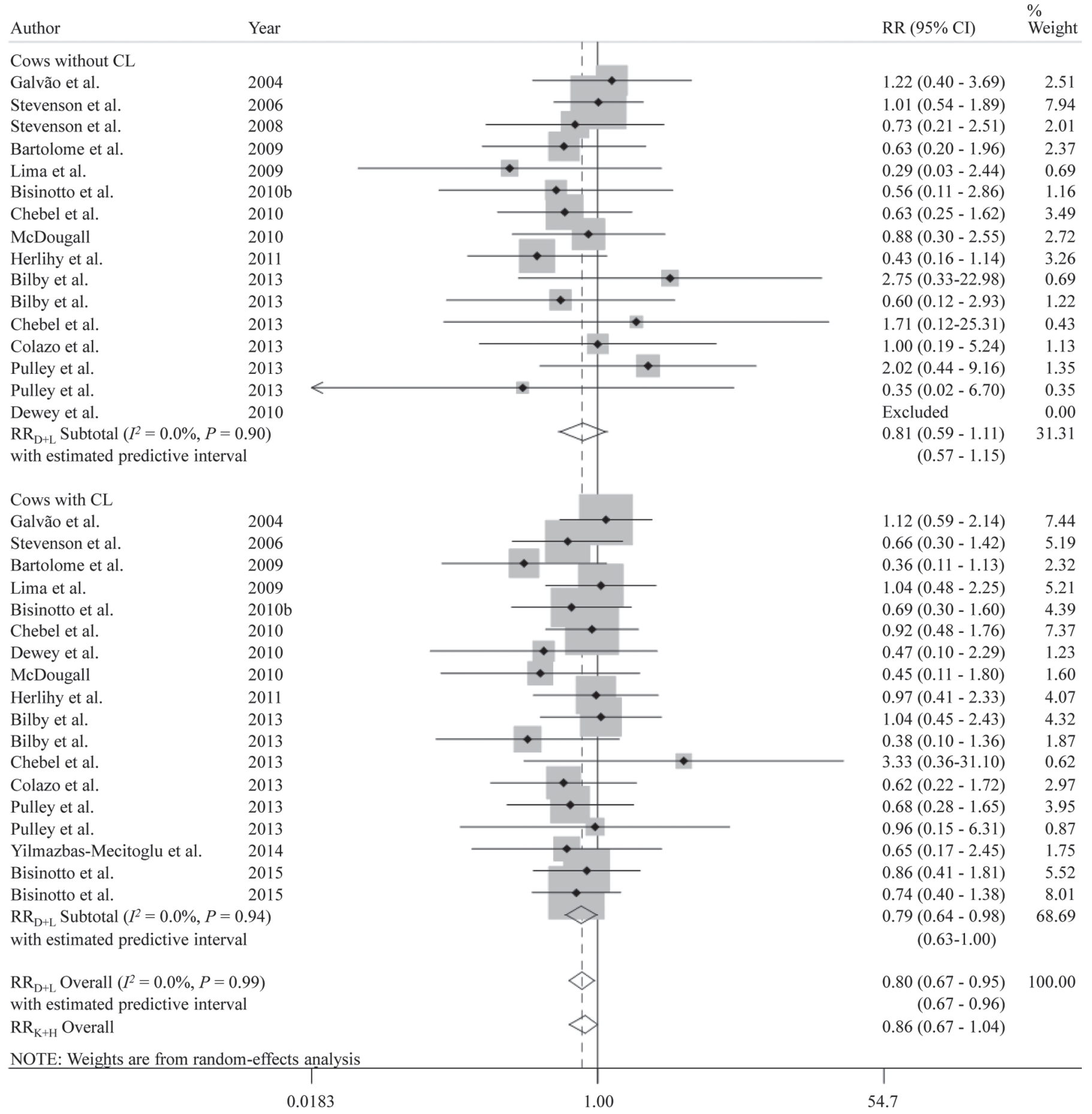

Figure 6. Effect of progesterone supplementation on the risk of pregnancy loss depending on the presence of corpus luteum (CL) at the initiation of the timed AI program. The weight (gray square), effect size (solid diamond), and the 95\% CI (whiskers) were depicted for each study. The overall effect size was summarized into a pooled risk ratio $\left(\mathrm{RR}_{\mathrm{D}+\mathrm{L}}\right.$; dashed line) and the final treatment effect is presented with the Knapp-Hartung modification $\left(\mathrm{RR}_{\mathrm{K}+\mathrm{H}}\right)$. Control cows were the reference for comparison. The width of the open diamond indicates $\mathrm{RR}_{\mathrm{D}+\mathrm{L}}$ and $\mathrm{RR}_{\mathrm{K}+\mathrm{H}} 95 \%$ CI. $I^{2}=$ proportion of total variation of effect size estimates that is due to heterogeneity.

spontaneous luteolysis and did not have a CL at the $\mathrm{PGF}_{2 \alpha}$ injection were greater in the late rather than the early resynchronization group. Accordingly, a treat- ment by day interaction was observed for pregnancy because progesterone supplementation increased $\mathrm{P} / \mathrm{AI}$ when resynchronization was initiated on d 39 but not 

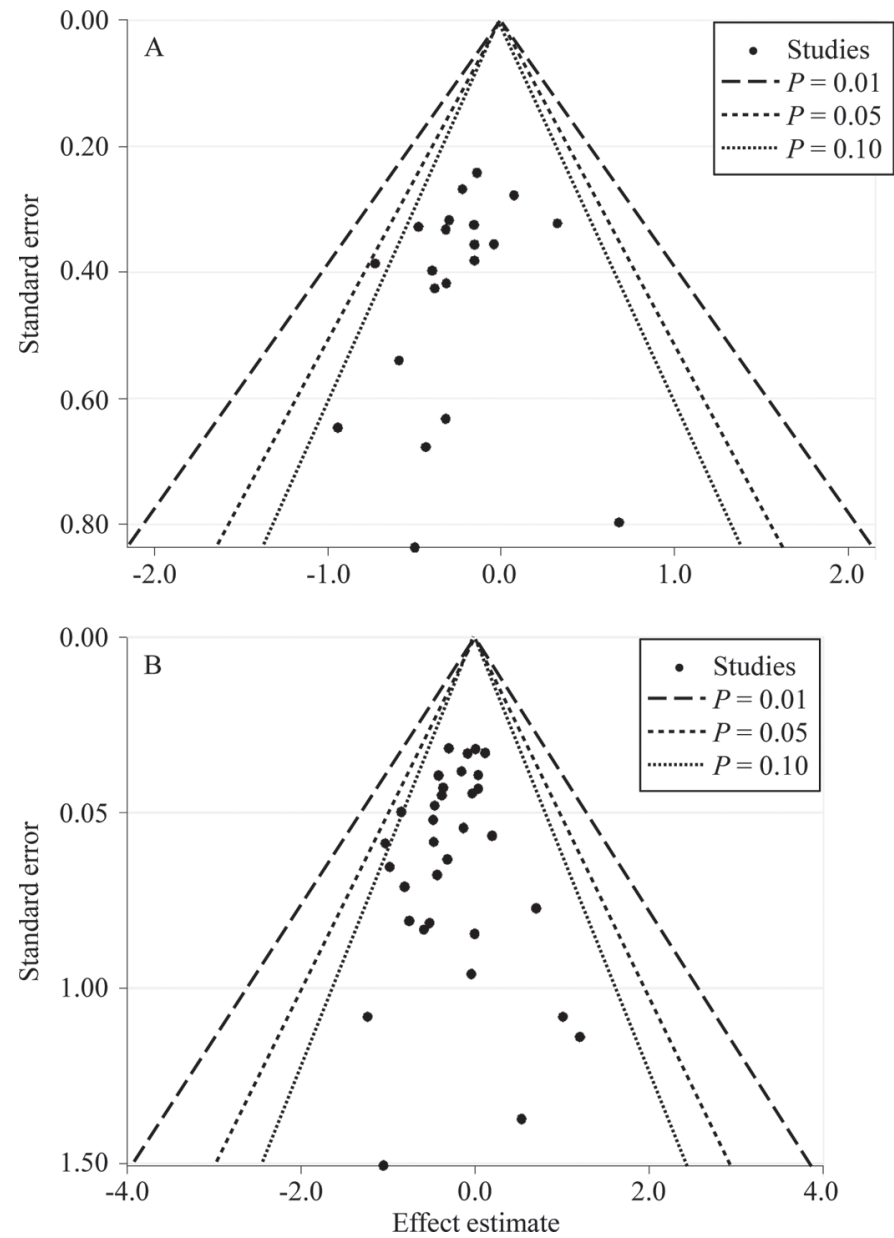

Figure 7. Contour-enhanced funnel plots for the risk of pregnancy loss in response to progesterone supplementation in all cows (A) and in cows with information on the presence of corpus luteum at the initiation of the timed AI program (B). Studies contained within the triangles have a significance value for the effect of progesterone supplementation greater than represented by the respective line (e.g., studies within the triangle contoured by the dotted lines have an effect of progesterone supplementation with a $P>0.10)$. Standard errors are inversely proportional to the number of cows in the study (smaller standard errors represent larger studies). Effect estimates represent the decrease in pregnancy loss associated with progesterone supplementation (values smaller than 0 indicate reduced pregnancy loss in cows supplemented with progesterone compared with controls).

on d 32 after AI. Collectively, these results emphasize the benefit of supplemental progesterone in improving synchrony of the estrous cycle and fertility to timed AI protocols in cows in which the CL regressed before the injection of $\mathrm{PGF}_{2 \alpha}$.

Presynchronization of the estrous cycle increases ovulation in response to the initial GnRH (Ribeiro et al., 2012) and the synchrony of ovulation at AI (El-Zarkouny et al., 2004), which could potentially attenuate the benefits of supplemental progesterone. Nevertheless, results from the current meta-analysis showed no effect of presynchronization on the response to progesterone on $\mathrm{P} / \mathrm{AI}$ or pregnancy loss. The presynchronization method implemented in the studies evaluated was based solely on the use of $\mathrm{PGF}_{2 \alpha}$, which is known to work only in estrous cyclic cows with a responsive CL (Moreira et al., 2001). Approximately 25\% of the dairy cows remain anovular when presynchronization is implemented (Stevenson et al., 2008; Santos et al., 2009; Bisinotto et al., 2010a), and these cows would not respond to the protocol, which would negate any effect on the response to supplemental progesterone during the timed AI. Also, cows that respond to the presynchronization with $\mathrm{PGF}_{2 \alpha}$ would likely have a CL on the day when the intravaginal insert is applied (Bisinotto et al., 2010a), which confounds the effect of presynchronization with that of presence of CL on the response to progesterone, both of which were evaluated in the meta-analysis. Unfortunately, the systematic review as performed does not allow us to evaluate the effect of presynchronization on the responses to progesterone only on estrous cyclic cows. Therefore, it is possible that response to progesterone during timed AI is enhanced in cows that do not receive presynchronization, although further studies are warranted to answer that specific question.

Five to $7 \%$ of the cows enrolled in timed AI programs were observed in estrus between the first $\mathrm{GnRH}$ and the $\mathrm{PGF}_{2 \alpha}$ injection of the protocol (Chebel et al., 2013; Bisinotto et al., 2015). If inseminated in estrus, these cows had similar P/AI compared with those that received timed AI (Chebel et al., 2013; Bisinotto et al., 2015). Conversely, cows in estrus during the synchronization protocol that are inseminated at scheduled timed AI are expected to have reduced fertility because of asynchrony between timing of ovulation and that of insemination. The use of intravaginal inserts containing progesterone prevents cows from coming in estrus during the treatment period (Bisinotto et al., 2015) and improves synchrony of ovulation in response to the timed AI program (Bisinotto et al., 2010b; Colazo et al., 2013). Except for 2 experiments reported by El-Zarkouny et al. (2004) in which progesterone supplementation numerically decreased $\mathrm{P} / \mathrm{AI}$, all 10 remaining studies (83\%) wherein detection of estrus was not performed showed a positive effect of supplemental progesterone. Because only nonsupplemented cows are expected to be inseminated before the injection of $\mathrm{PGF}_{2 \alpha}$ (Bisinotto et al., 2015), the benefit from detection of estrus on reducing the negative effect of asynchronous ovulation is potentially greater in control cows. In fact, positive effects of progesterone supplementation $(\mathrm{RR}>1)$ were found in only 7 of 13 studies (54\%) in which cows were observed for signs of estrus and inseminated before scheduled 
timed AI. When detection of estrus was included in the analyses with all cows or in the analyses of the subset of cows with CL information, the benefit of progesterone supplementation declined. For all studies, the benefit of progesterone supplementation was reduced from 19 to a nonsignificant $3 \%\left(\mathrm{RD}_{\mathrm{K}+\mathrm{H}}=-0.16\right.$; Table 3$)$. A similar reduction $\left(\mathrm{RD}_{\mathrm{K}+\mathrm{H}}=-0.14\right.$; Table 4$)$ in the benefit of progesterone was observed when only studies with CL information were considered. Collectively, these results indicate that the benefit of supplementing progesterone during timed AI protocols are observed when all cows are inseminated at a fixed time; thus, implementing detection of estrus and AI throughout the protocol will diminish the benefit of progesterone on fertility of cows subjected to time insemination. These results help explain the lack of consistency in the response to progesterone supplementation in the literature, which seems to be mediated to a large extent by the reproductive management implemented on the farm.

Previously, a narrative review of the literature by our group suggested that a single intravaginal progesterone insert during the timed AI protocol did not improve $\mathrm{P} / \mathrm{AI}$ of anovular cows, but did improve that of cows with a CL when the protocol was initiated (Bisinotto and Santos, 2011). Contrary to our initial hypothesis, the benefit of exogenous progesterone on $\mathrm{P} / \mathrm{AI}$ was observed mainly in cows without a CL at the initiation of the timed AI program. The greater benefit of progesterone supplementation in cows without a CL is likely mediated by effects on synchronization of ovulation, follicle or oocyte maturation, and endometrial function.

Ninety to $95 \%$ of the cows in diestrus at the initiation of the timed AI program are expected to have a CL at the injection of $\mathrm{PGF}_{2 \alpha}$ (Stevenson et al., 2008; Bisinotto et al., 2013). Conversely, only $75 \%$ of the cows without CL when the timed AI program is initiated present a newly formed $\mathrm{CL}$ at the injection of $\mathrm{PGF}_{2 \alpha}$ (Stevenson et al., 2008; Bisinotto et al., 2013). Cows without a CL have increased occurrence of asynchronous ovulation at timed AI compared with cows in diestrus (Vasconcelos et al., 1999; Bisinotto et al., 2013). Therefore, supplementing progesterone to these cows without a CL would eliminate expression of estrus and ovulation during the period of treatment, thereby improving synchrony between induced ovulation and timing of AI. Such benefits would be more clearly observed in farms in which all cows are subjected to timed AI and no detection of estrus is performed. Indeed, studies have documented the benefit of intravaginal progesterone inserts on the synchrony of ovulation (Bisinotto et al., 2010b; Colazo et al., 2013).

Concentrations of progesterone during the development of the ovulatory follicle are approximately 3.0 $\mathrm{ng} / \mathrm{mL}$ greater in cows with a developed CL compared with anovular cows or estrous cyclic cows not in diestrus (Cerri et al., 2009a; Rivera et al., 2011; Bisinotto et al., 2013). High concentrations of progesterone during the development of the ovulatory follicle reduces the rate of follicle growth (Cerri et al., 2011a,b), increases concentrations of IGF-1 in the follicular fluid (Cerri et al., 2011a), improves early embryo quality (Rivera et al., 2011), and enhances P/AI (Bisinotto et al., 2010a, 2013). Conversely, concentrations of progesterone in plasma of lactating dairy cows increase only approximately $0.8 \mathrm{ng} / \mathrm{mL}$ in response to a single intravaginal insert (Cerri et al., 2009a; Lima et al., 2009), which is low compared with those observed in cows bearing a CL (Cerri et al., 2011b). This low concentration of progesterone was insufficient to alter the diameter of the ovulatory follicle in cows subjected to timed AI (El-Zarkouny et al., 2004; Dewey et al., 2010; Colazo et al., 2013) or to timed AI in combination with detection of estrus (Lima et al., 2009; Bisinotto et al., 2010b, 2015). Although we cannot completely exclude an effect on the follicle and oocyte, increments of 0.8 $\mathrm{ng} / \mathrm{mL}$ of progesterone in plasma of cows without an active CL might be insufficient to improve P/AI mediated by changes in the early embryo, as observed with supplementation with multiple inserts (Rivera et al., 2011).

Progesterone might have also influenced endometrial function in the cycle subsequent to insemination. Such an effect might benefit early embryo development to improve establishment and maintenance of pregnancy in dairy cows. The present meta-analysis showed not only that progesterone improved P/AI, but also tended to reduce the risk of pregnancy loss in the first $60 \mathrm{~d}$ of gestation. The benefit of progesterone in reducing pregnancy loss, however, was observed independently of the presence of CL. Although the detrimental effect of suboptimal progesterone concentrations during follicle growth on embryo quality are noticeable as early as the first week after insemination (Rivera et al., 2011), it is possible that some of the pathways affected by changes in progesterone concentrations are not limited to the early embryo. For instance, Shaham-Albalancy et al. (1997) reported changes in uterine gland morphology and vascularization in response to progesterone supplementation preovulation, which might affect subsequent placentation and late embryo and fetal mortality. Low progesterone in the cycle preceding ovulation resulted in altered endometrial expression of proteins linked to luteolysis and increased the release of $\mathrm{PGF}_{2 \alpha}$ after an oxytocin challenge (Cerri et al., 2011a). Therefore, adequate progesterone during development of the ovulatory follicle not only influences establishment of pregnancy, but might also have legacy effects that alter maintenance of gestation in dairy cows. 


\section{CONCLUSIONS}

Progesterone supplementation during the growth of the ovulatory follicle improved fertility responses in lactating dairy cows. The incorporation of a single intravaginal insert from the first GnRH to the injection of $\mathrm{PGF}_{2 \alpha}$ increased pregnancy by 8 and $10 \%$ on $\mathrm{d} 32$ and 60 after AI, respectively. The benefit of progesterone supplementation was observed primarily in cows without CL at the initiation of the synchronization protocol. Insemination of cows in estrus during the synchronization protocol reduced the benefit of progesterone supplementation, and this effect was observed in cows with or without CL when the timed AI program was initiated. Finally, supplementing progesterone during the development of the ovulatory follicle tended to reduce the risk of pregnancy loss. Collectively, these results explain the heterogeneity of the effect of progesterone supplementation observed in the literature and outline physiological and managerial conditions in which supplemental progesterone enhances fertility in lactating dairy cows subjected to timed AI protocols.

\section{ACKNOWLEDGMENTS}

The authors thank Jeffrey S. Stevenson (Kansas State University, Manhattan), Klibs N. Galvão (University of Florida), Marcos G. Colazo (Alberta Agriculture and Rural Development, Edmonton, Canada), Ricardo C. Chebel (University of Florida), Scott McDougall (Anexa Animal Health, Morrinsville, New Zealand), Stephanie L. Pulley (Arkansas State University, Jonesboro), Stephen T. Butler (Teagasc, Fermoy, Ireland), and Todd R. Bilby (Merck Animal Health, Summit, NJ) for providing supplemental data to be included in the present study.

\section{REFERENCES}

Bartolome, J. A., J. J. van Leeuwen, M. Thieme, O. G. Sá Filho, P. Melendez, L. F. Archbald, and W. W. Thatcher. 2009. Synchronization and resynchronization of inseminations in lactating dairy cows with the CIDR insert and the Ovsynch protocol. Theriogenology 72:869-878.

Bilby, T. R., R. G. Bruno, K. J. Lager, R. C. Chebel, J. G. Moraes, P. M. Fricke, G. Lopes Jr., J. O. Giordano, J. E. P. Santos, F. S. Lima, J. S. Stevenson, and S. L. Pulley. 2013. Supplemental progesterone and timing of resynchronization on pregnancy outcomes in lactating dairy cows. J. Dairy Sci. 96:7032-7042.

Bisinotto, R. S., R. C. Chebel, and J. E. P. Santos. 2010a. Follicular wave of the ovulatory follicle and not cyclic status influences fertility of dairy cows. J. Dairy Sci. 93:3578-3587.

Bisinotto, R. S., M. B. Pansani, L. O. Castro, C. D. Narciso, L. D. P. Sinedino, N. Martinez, P. E. Carneiro, W. W. Thatcher, and J. E. P. Santos. 2015. Effect of progesterone supplementation on fertility responses of lactating dairy cows with corpus luteum at the initiation of the Ovsynch protocol. Theriogenology 83:257-265.
Bisinotto, R. S., E. S. Ribeiro, F. S. Lima, N. Martinez, L. F. Greco, L. F. S. P. Barbosa, P. P. Bueno, L. F. S. Scagion, W. W. Thatcher, and J. E. P. Santos. 2013. Targeted progesterone supplementation improves fertility in lactating dairy cows without a corpus luteum at the initiation of the timed artificial insemination protocol. J. Dairy Sci. 96:2214-2225.

Bisinotto, R. S., E. S. Ribeiro, L. T. Martins, R. S. Marsola, L. F Greco, M. G. Favoreto, C. A. Risco, W. W. Thatcher, and J. E. P. Santos. 2010b. Effect of interval between induction of ovulation and artificial insemination (AI) and supplemental progesterone for resynchronization on fertility of dairy cows subjected to a 5-d timed AI program. J. Dairy Sci. 93:5798-5808.

Bisinotto, R. S., E. S. Ribeiro, and J. E. P. Santos. 2014. Synchronisation of ovulation for management of reproduction in dairy cows. Animal 8(Suppl. 1):151-159.

Bisinotto, R. S., and J. E. P. Santos. 2011. The use of endocrine treatments to improve pregnancy rates in cattle. Reprod. Fertil. Dev. 24:258-266.

Bleach, E. C., R. G. Glencross, and P. G. Knight. 2004. Association between ovarian follicle development and pregnancy rates in dairy cows undergoing spontaneous oestrous cycles. Reproduction 127:621-629.

Cerri, R. L., R. C. Chebel, F. Rivera, C. D. Narciso, R. A. Oliveira, M Amstalden, G. M. Baez-Sandoval, L. J. Oliveira, W. W. Thatcher, and J. E. P. Santos. 2011a. Concentration of progesterone during the development of the ovulatory follicle: II. Ovarian and uterine responses. J. Dairy Sci. 94:3352-3365.

Cerri, R. L., R. C. Chebel, F. Rivera, C. D. Narciso, R. A. Oliveira, W. W. Thatcher, and J. E. P. Santos. 2011b. Concentration of progesterone during the development of the ovulatory follicle: I. Ovarian and embryonic responses. J. Dairy Sci. 94:3342-3351.

Cerri, R. L., H. M. Rutigliano, R. G. Bruno, and J. E. P. Santos. 2009a. Progesterone concentration, follicular development and induction of cyclicity in dairy cows receiving intravaginal progesterone inserts. Anim. Reprod. Sci. 110:56-70.

Cerri, R. L., H. M. Rutigliano, R. C. Chebel, and J. E. P. Santos 2009b. Period of dominance of the ovulatory follicle influences embryo quality in lactating dairy cows. Reproduction 137:813-823.

Chebel, R. C., M. J. Al-Hassan, P. M. Fricke, J. E. P. Santos, J. R. Lima, C. A. Martel, J. S. Stevenson, R. Garcia, and R. L. Ax. 2010. Supplementation of progesterone via controlled internal drug release inserts during ovulation synchronization protocols in lactating dairy cows. J. Dairy Sci. 93:922-931.

Chebel, R. C., A. A. Scanavez, P. R. Silva, J. G. Moraes, L. G. Mendonça, and G. Lopes Jr. 2013. Evaluation of presynchronized resynchronization protocols for lactating dairy cows. J. Dairy Sci. 96:1009-1020.

Colazo, M. G., A. Dourey, R. Rajamahendran, and D. J. Ambrose. 2013. Progesterone supplementation before timed AI increased ovulation synchrony and pregnancy per AI, and supplementation after timed AI reduced pregnancy losses in lactating dairy cows. Theriogenology 79:833-841.

Denicol, A. C., G. Lopes Jr., L. G. Mendonça, F. A. Rivera, F. Guagnini, R. V. Perez, J. R. Lima, R. G. Bruno, J. E. P. Santos, and R. C. Chebel. 2012. Low progesterone concentration during the development of the first follicular wave reduces pregnancy per insemination of lactating dairy cows. J. Dairy Sci. 95:1794-1806.

DerSimonian, R., and N. Laird. 1986. Meta-analysis in clinical trials. Control. Clin. Trials 7:177-188.

Dewey, S. T., L. G. Mendonça, G. Lopes Jr., F. A. Rivera, F. Guagnini, R. C. Chebel, and T. R. Bilby. 2010. Resynchronization strategies to improve fertility in lactating dairy cows utilizing a presynchronization injection of GnRH or supplemental progesterone: I. Pregnancy rates and ovarian responses. J. Dairy Sci. 93:4086-4095.

Egger, M., and G. D. Smith. 2001. Principles of and procedures for systematic reviews. Pages 23-42 in Systematic Reviews in Health Care: Meta-Analysis in Context. M. Egger, G. D. Smith, and D.G. Altman, ed. British Medical Journal Books, London, UK.

El-Zarkouny, S. Z., J. A. Cartmill, B. A. Hensley, and J. S. Stevenson. 2004. Pregnancy in dairy cows after synchronized ovulation 
regimens with or without presynchronization and progesterone. J. Dairy Sci. 87:1024-1037.

Folman, Y., M. Rosenberg, Z. Herz, and M. Davidson. 1973. The relationship between plasma progesterone concentration and conception in post-partum dairy cows maintained on two levels of nutrition. J. Reprod. Fertil. 34:267-278.

Fonseca, F. A., J. H. Britt, B. T. McDaniel, J. C. Wilk, and A. H. Rakes. 1983. Reproductive traits of Holsteins and Jerseys. Effects of age, milk yield, and clinical abnormalities on involution of cervix and uterus, ovulation, estrous cycles, detection of estrus, conception rate, and days open. J. Dairy Sci. 66:1128-1147.

Fricke, P. M., D. Z. Caraviello, K. A. Weigel, and M. L. Welle. 2003. Fertility of dairy cows after resynchronization of ovulation at three intervals following first timed insemination. J. Dairy Sci. 86:3941-3950.

Galvão, K. N., J. E. P. Santos, S. O. Juchem, R. L. Cerri, A. C. Coscioni, and M. Villasenor. 2004. Effect of addition of a progesterone intravaginal insert to a timed insemination protocol using estradiol cypionate on ovulation rate, pregnancy rate, and late embryonic loss in lactating dairy cows. J. Anim. Sci. 82:3508-3517.

Herlihy, M. M., D. P. Berry, M. A. Crowe, M. G. Diskin, and S. T. Butler. 2011. Evaluation of protocols to synchronize estrus and ovulation in seasonal calving pasture-based dairy production systems. J. Dairy Sci. 94:4488-4501.

Higgins, J. P., S. G. Thompson, J. J. Deeks, and D. G. Altman. 2003 Measuring inconsistency in meta-analyses. BMJ 327:557-560.

Knapp, G., and J. Hartung. 2003. Improved tests for a random effects meta-regression with a single covariate. Stat. Med. 22:2693-2710.

Lean, I. J., A. R. Rabiee, T. F. Duffield, and I. R. Dohoo. 2009. Invited review: Use of meta-analysis in animal health and reproduction: Methods and applications. J. Dairy Sci. 92:3545-3565.

Lima, J. R., F. A. Rivera, C. D. Narciso, R. Oliveira, R. C. Chebel, and J. E. P. Santos. 2009. Effect of increasing amounts of supplemental progesterone in a timed artificial insemination protocol on fertility of lactating dairy cows. J. Dairy Sci. 92:5436-5446.

McDougall, S. 2010. Effects of treatment of anestrous dairy cows with gonadotropin-releasing hormone, prostaglandin, and progesterone. J. Dairy Sci. 93:1944-1959.

Meisterling, E. M., and R. A. Dailey. 1987. Use of concentrations of progesterone and estradiol-17 beta in milk in monitoring postpartum ovarian function in dairy cows. J. Dairy Sci. 70:2154-2161.

Melendez, P., G. Gonzalez, E. Aguilar, O. Loera, C. Risco, and L. F. Archbald. 2006. Comparison of two estrus-synchronization protocols and timed artificial insemination in dairy cattle. J. Dairy Sci. 89:4567-4572.

Moore, S. G., S. Scully, J. A. Browne, T. Fair, and S. T. Butler. 2014. Genetic merit for fertility traits in Holstein cows: V. Factors affecting circulating progesterone concentrations. J. Dairy Sci. 97:5543-5557.

Moreira, F., C. Orlandi, C. A. Risco, R. Mattos, F. Lopes, and W. W. Thatcher. 2001. Effects of presynchronization and bovine somatotropin on pregnancy rates to a timed artificial insemination protocol in lactating dairy cows. J. Dairy Sci. 84:1646-1659.

Pulley, S. L., S. L. Hill, and J. S. Stevenson. 2013. Five-day Resynch programs in dairy cows including the CIDR at two stages postartificial insemination. J. Dairy Sci. 96(Suppl. 1):351 (abstract).

Rabiee, A. R., and I. J. Lean. 2013. The effect of internal teat sealant products (Teatseal and Orbeseal) on intramammary infection, clinical mastitis, and somatic cell counts in lactating dairy cows: a meta-analysis. J. Dairy Sci. 96:6915-6931.

Rabiee, A. R., I. J. Lean, and M. A. Stevenson. 2004. A Bayesian meta-analysis of the effects of administering an intra-vaginal (CIDR) device in combination with other hormones on the reproductive performance of cycling, anoestrous and inseminated cows. N. Z. Vet. J. $52: 384-393$.

Ribeiro, E. S., R. S. Bisinotto, M. G. Favoreto, L. T. Martins, R. L. A Cerri, F. T. Silvestre, L. F. Greco, W. W. Thatcher, and J. E. P. Santos. 2012. Fertility in dairy cows following presynchronization and administering twice the luteolytic dose of prostaglandin $\mathrm{F}_{2 \mathrm{\alpha}}$ as one or two injections in the 5-day timed artificial insemination protocol. Theriogenology 78:273-284.

Rivera, F. A., L. G. Mendonca, G. Lopes Jr., J. E. P. Santos, R. V. Perez, M. Amstalden, A. Correa-Calderon, and R. C. Chebel. 2011. Reduced progesterone concentration during growth of the first follicular wave affects embryo quality but has no effect on embryo survival post transfer in lactating dairy cows. Reproduction 141:333-342.

Sangsritavong, S., D. K. Combs, R. Sartori, L. E. Armentano, and M. C. Wiltbank. 2002. High feed intake increases liver blood flow and metabolism of progesterone and estradiol-17beta in dairy cattle. J. Dairy Sci. 85:2831-2842.

Santos, J. E. P., H. M. Rutigliano, and M. F. Sá Filho. 2009. Risk factors for resumption of postpartum estrous cycles and embryonic survival in lactating dairy cows. Anim. Reprod. Sci. 110:207-221.

Sartori, R., J. M. Haughian, R. D. Shaver, G. J. Rosa, and M. C. Wiltbank. 2004. Comparison of ovarian function and circulating steroids in estrous cycles of Holstein heifers and lactating cows. J. Dairy Sci. 87:905-920.

Sartori, R., R. Sartor-Bergfelt, S. A. Mertens, J. N. Guenther, J. J. Parrish, and M. C. Wiltbank. 2002. Fertilization and early embryonic development in heifers and lactating cows in summer and lactating and dry cows in winter. J. Dairy Sci. 85:2803-2812.

Shaham-Albalancy, A., A. Nyska, M. Kaim, M. Rosenberg, Y. Folman, and D. Wolfenson. 1997. Delayed effect of progesterone on endometrial morphology in dairy cows. Anim. Reprod. Sci. 48:159-174.

Stevenson, J. S., J. R. Pursley, H. A. Garverick, P. M. Fricke, D. J. Kesler, J. S. Ottobre, and M. C. Wiltbank. 2006. Treatment of cycling and noncycling lactating dairy cows with progesterone during Ovsynch. J. Dairy Sci. 89:2567-2578.

Stevenson, J. S., D. E. Tenhouse, R. L. Krisher, G. C. Lamb, J. E. Larson, C. R. Dahlen, J. R. Pursley, N. M. Bello, P. M. Fricke, M. C. Wiltbank, D. J. Brusveen, M. Burkhart, R. S. Youngquist, and H. A. Garverick. 2008. Detection of anovulation by heatmount detectors and transrectal ultrasonography before treatment with progesterone in a timed insemination protocol. J. Dairy Sci. 91:2901-2915.

Vasconcelos, J. L., R. W. Silcox, G. J. Rosa, J. R. Pursley, and M. C. Wiltbank. 1999. Synchronization rate, size of the ovulatory follicle, and pregnancy rate after synchronization of ovulation beginning on different days of the estrous cycle in lactating dairy cows. Theriogenology 52:1067-1078.

Walsh, R. B., S. J. Leblanc, T. F. Duffield, D. F. Kelton, J. S. Walton, and K. E. Leslie. 2007. The effect of a progesterone releasing intravaginal device (PRID) on pregnancy risk to fixed-time insemination following diagnosis of non-pregnancy in dairy cows. Theriogenology 67:948-956.

Wiltbank, M. C., A. H. Souza, P. D. Carvalho, A. P. Cunha, J. O. Giordano, P. M. Fricke, G. M. Baez, and M. G. Diskin. 2014. Physiological and practical effects of progesterone on reproduction in dairy cattle. Animal 8(Suppl. 1):70-81.

Yilmazbas-Mecitoglu, G., E. Karakaya, A. Keskin, A. Gümen, V. Koc, and H. Okut. 2014. Comparison of synchronisation and fertility after different modifications of the ovsynch protocol in cyclic dairy cows. Acta Vet. Hung. 62:64-73. 